\title{
SELEÇÃO INICIAL E CARACTERIZAÇÃO PARCIAL DE RIZÓBIOS DE TABULEIROS COSTEIROS QUANDO ASSOCIADOS AO GUANDU ${ }^{(1)}$
}

\author{
M. F.FERNANDES ${ }^{(2)} \&$ R.P.M. MERNANDES ${ }^{(3)}$
}

\begin{abstract}
RESUMO
O objetivo deste trabal ho foi selecionar e caracterizar parcialmente rizóbios de tabuleiros costeiros com alta capacidade de fixação biológica do $\mathrm{N}$, quando associados ao guandu. Dezesseis isolados de rizóbios de diferentes regiões desse ecossistema foram avaliados em casa de vegetação da Embrapa Tabuleiros Costeiros (Aracaju, SE ). Quatro isolados destacaram-se quanto ao $\mathbf{N}$ acumulado $\left(N_{a c}\right)$, matéria seca da parte aérea (MSPA), área foliar (AF) e matéria seca de nódulos (MSN). A MSN correlacionou-se com a MSPA, AF e $\mathbf{N}_{\mathrm{ac}}$. A relação $\mathbf{N}$ ureído/N-total na seiva xilemática correlacionou-se com $\mathbf{N}_{\mathrm{ac}}$ e MSN. Três desses isolados foram caracterizados (R 1, R 5 e R 11) e apresentaram cresci mento rápido e acidificaram o meio de cultura com manitol. Comparado ao R1 e R5, o isolado R11 foi o mais sensível aos anti bióticos e o menos tolerante ao Al eàs temperaturas elevadas.
\end{abstract}

Termos de indexação: alumínio, antibiótico, N-ureído, temperatura, Cajanus cajan.

SUMMARY: INITIAL SCREENING AND PARTIAL CHARACTERIZATION OF RHIZOBIA FROM A BRAZILIAN COASTAL TABLELAND WHEN ASSOCIATED TO PIGEONPEA

The aim of this study was to sel ect and partially characterize efficient nitrogen-fixing rhizobia associated to pigeonpea from coastal tableland areas in the Northeast of Brazil. Sixteen rhizobia from different coastal tableland areas were evaluated under greenhouse condition, at the Embrapa Coastal Tablelands (Aracaju, Sergipe, Brazil). Four isolates performed better than theothers in rel ation to shoot N content (NC), shoot dry weight (SDW),

(1) Trabal ho financiado pela F undação Banco do Brasil. Recebido para publicação em novembro de 1999 e aprovado em abril de 2000.

(2) Pesquisador da Embrapa Tabuleiros Costeiros. Av. Beira Mar 3250, CEP 49025-040 Aracaju (SE). E-mail: marcelo@cpatc.embrapa.br

(3) Professora Assistente do Departamento de Fisiologia, Universidade Federal de Sergipe - UFS. CEP 49100-000 São Cristóvão (SE). 
leaf area (LA) and noduledry weight (NDW). NDW showed high correlation with SDW, LA and NC. Xylem sap N-ure de/ N-total ratio showed high correlation with NC and NDW. The threechosen isol ates (R1, R5 and R11) showed fast growth rateand acidified culturemedium with manni tol. Compared to R 1 and R5, theisolateR 11 was moresensitiveto theanti biotics and less tol erant to $\mathrm{Al}$ and high temperature.

Index terms: al uminum, antibi otic, $\mathrm{N}$-ureide, temperature, Cajanus cajan.

\section{NTRODUÇÃO}

Em estudos realizados em área do ecossistema de tabuleiro costeiro de Sergipe, observou-se que a inoculação de leguminosas com estirpes recomendadas para outras regiões do País fal hou em incrementar o crescimento vegetal, os teores de $\mathrm{N}$ e a nodulação das plantas (Barreto \& Fernandes, 1998). Possíveis causas da ausência de resposta à inoculação estão relacionadas com a baixa capacidade dessas estirpes em colonizar efetivamente as raízes, quando introduzi das em sol o com uma população de rizóbios nativos estabelecida (Thies et al., 1991), ou com a baixa adaptabilidade das estirpes às condições edafocl imáticas da região.

Desse modo, para que a inoculação com rizóbios seja bem-sucedida, a estirpe deve apresentar, além de alta eficiência simbiótica, características de sobrevivência no sol o e habilidade competitiva com a população rizobiana nativa (Brockwell, 1981). Tais características têm sido freqüentemente relacionadas com a maior resistência das estirpes a antibióticos, ao Al ea temper aturas el evadas, dentre outros fatores (Oliveira \& Graham, 1990; Wolff et al., 1991; Xavier et al., 1998).

O objetivo desteestudo foi selecionar ecaracterizar estirpes de rizóbios dos tabuleiros costeiros de Sergipe adaptadas às condições locais e com alta capacidade de fixação biológica do nitrogênio (FBN), visando obter inoculante eficiente para guandu.

\section{MATERIAL E MÉTODOS}

Raízes de guandu (Cajanus cajan), feijão-de-porco (Canavalia ensiformis) e caupi (Vigna unguiculata) foram col etadas em diferentes áreas de tabuleiros costeiros de Sergipe (Quadro 1). O isolamento dos rizóbios a partir dos nódulos foi realizado em meio YMA com vermelho Congo, de acordo com Vincent (1970).

O efeito da inoculação do guandu com 16 isol ados de rizóbios sobre o crescimento vegetal e FBN foi avaliado em experimento instalado em casa de vegetação, da Embrapa Tabuleiros Costeiros (Aracaju, SE). O delineamento experimental utilizado foi o inteiramente casualizado, com seis repetições.
Quatro tratamentos adicionais sem inoculação e com adição de doses crescentes de $\mathrm{N}$ foram incluídos. Utilizaram-se vasos de L eonard com capacidade de $1 \mathrm{~L}$ em cada compartimento. Nos vasos dos tratamentos inoculados com rizóbios e nos da testemunha absoluta (sem inoculação e sem adição de $\mathrm{N}$ mineral), o compartimento superior foi preenchido com vermiculita, e o inferior, com sol ução nutritiva livre desse nutriente(Weaver \& F rederick, 1982). Nos tratamentos com $\mathrm{N}$ mineral, a solução nutritiva foi a mesma, porém acrescida de $\mathrm{NH}_{4} \mathrm{NO}_{3}$ nas concentrações de 50, 100 ou 150 mg L-1 de N.

Três sementes de guandu desinfestadas com hi pocl orito de sódi o $6 \%$ (6 $\mathrm{min}$ ) foram plantadas por vaso. Após uma semana do plantio, foi realizado o desbaste, deixando-se apenas uma planta por vaso. A inoculação com as estirpes de rizóbios foi feita no momento de plantio, utilizando-se $3 \mathrm{~mL}$ desuspensões de rizóbios por vaso. O inóculo foi padronizado para umvalor deabsorvância ( $\lambda=600 \mathrm{~nm}$ ) igual a 1,0, após centrifugação das culturas por três min a 4.000 rpm. Os vasos dos tratamentos não inoculados receberam $3 \mathrm{~mL}$ de uma suspensão de rizóbio previamente autocl avada. Os compartimentos inferiores dos vasos de Leonard foram completados a cada três dias com a solução nutritiva livre de $\mathrm{N}$.

O experimento foi coletado 60 dias após o plantio, cortando-se as plantas na altura do nó cotiledonar. A seiva xilemática exsudada na região do corte foi coletada por $30 \mathrm{~min}$. Os teores de N-ureídos (Vogels \& van der Drift, 1970) eN-total (Bohley, 1967, citado por Hungria, 1994) da seiva foram determinados para estimar a percentagem de $\mathrm{N}$-ureído na seiva do xilema [(N-ureído/ $\mathrm{N}$-total $) \times 100]$.

A área foliar (AF) foi obtida utilizando-se um aparelho Li-Cor. A matéria seca da parte aérea (MSPA) e a matéria seca de nódulos (MSN) foram determinadas após secagem desses materiais em estufa a $65^{\circ} \mathrm{C}$, por $72 \mathrm{~h}$.

Os teores de $\mathrm{N}$ na parte aérea foram analisados pelo método de Kjeldhal para obtenção dos valores de $\mathrm{N}$ acumulado $\left(\mathrm{N}_{\mathrm{ac}}\right)$.

Os isolados R1, R5 e R11 foram selecionados para a etapa de caracterização, por estarem entre os mais promissores, de acordo com os resultados obtidos em vasos de Leonard.

Alíquotas de diluições seriadas de culturas dos isolados crescidos em YM líquido (28ㄷ) foram 
Quadro 1. I solados de rizóbios nativos de tabuleiros costeiros de Sergipe e respectivas espécies hospedeiras e locais de origem ${ }^{(1)}$

\begin{tabular}{lll}
\hline Isolado & \multicolumn{1}{c}{ Espécie } & Local \\
\hline R1 & Guandu & N.S. Dores \\
R2 & Guandu & Aracaju \\
R3 & Guandu & Umbaúba \\
R4 & Feijão-de-porco & Lagarto \\
R5 & Feijão-de-corda & Aracaju \\
R6 & Guandu & Aracaju \\
R7 & Guandu & Umbaúba \\
R8 & Feijão-de-corda & Umbaúba \\
R9 & Guandu & Umbaúba \\
R10 & Feijão-de-corda & Lagarto \\
R11 & Guandu & Lagarto \\
R12 & Feijão-de-corda & Aracaju \\
R13 & Feijão-de-porco & Lagarto \\
R14 & Feijão-de-porco & Lagarto \\
R15 & Feijão-de-corda & Umbaúba \\
R16 & Guandu & Umbaúba \\
\hline
\end{tabular}

(1) Os isolados de mesma espécie e mesmo local foram obtidos de nódulos provenientes de plantas distintas, localizadas a, pelo menos, 50 m entre si.

plaqueadas, a cada intervalo de duas horas de incubação, em meio YMA, para determinar o tempo de geração das bactérias. A pós incubação das placas de YMA ( $\left.36 \mathrm{~h}, 2^{\circ} \mathrm{C}\right)$ ), procedeu-se à contagem das unidades formadoras de colônias sob microscópio estereoscópico. Para calcular o tempo de geração, consideraram-se apenas os valores de concentração bacteriana incluídos na fase logarítmica da curva de crescimento.

A reação ácida ou básica durante o crescimento das bactérias foi avaliada em meio YMA com azul de bromotimol aos dois e quatro dias de incubação a $28 \mathrm{C}$.

A tolerância dos três isolados ao Al ea diferentes temperaturas foi avaliada pela medição do diâmetro das colônias crescidas em meio YMA, após quatro dias de incubação. Para o ensai o com Al, o meio YMA foi acrescido de sulfato de al umínio em quantidades suficientes para obtenção de concentrações aproximadas de $0,5,10,20$ e $50 \mathrm{mg} \mathrm{L}^{-1}$ de $A \mathrm{I}$, sendo a incubação das culturas realizada a $28^{\circ} \mathrm{C}$. Para o ensai o detemperatura, avaliou-se o crescimento dos isolados a 28, 32 e $42^{\circ} \mathrm{C}$.

A resistência intrínseca dos três isolados de rizóbios aos antibióticos tetraciclina, ampicilina, kanamicina, cloranfenicol, estreptomicina e ácido nalidíxico foi determinada pela técnica de gradiente deconcentração em placa. Utilizou-se mei oYMA com gradiente de concentrações de anti bióticos variando de 0 a $500 \mathrm{mg} \mathrm{L-1.} \mathrm{A} \mathrm{avaliação} \mathrm{foi} \mathrm{feita} \mathrm{após} \mathrm{quatro}$ dias de incubação a ${ }^{20}$ C. Atribuíram-se notas de 0 a 3, caso o crescimento bacteriano ocorresse, respectivamente, em faixas de concentrações de antibióticos de 0 a 125; 126 a 250; 251 a 375 ou 376 a $500 \mathrm{mg} \mathrm{L}^{-1}$.

Determinaram-se, por meio de eletroforese em gel de poliacrilamida (Laemmli, 1970), os perfis de proteínas solúveis totais dos três isol ados nativos e de duas estirpes de crescimento lento provenientes da Embrapa Agrobiologia (Seropédica, RJ ), sendo uma recomendada para guandu e outra para caupi. As amostras de proteínas para aplicação ao gel de poliacrilamida foram preparadas de acordo com protocolo proposto por R.S. Araújo (Hungria et al., 1994). A quantidade de proteína (Bradford, 1976) adicionada em cada poço foi ajustada para 10 a $20 \mu \mathrm{g}$.

\section{RESULTADOSE DISCUSSÃO}

Dentre os isolados avaliados, R1, R8 e R11 promoveram os mai ores incrementos da MSPA e da AF, com destaque para o primeiro. Estes isolados, juntamente com o R5, resultaram em maiores val ores de Nac (Quadro 2), superando o tratamento com a maior dose de $\mathrm{N}$ mineral (150 mg L-1). Considerando o reduzi do val or do $\mathrm{N}_{\mathrm{ac}}$ de plantas não inoculadas e livres de $\mathrm{N}$ mineral (4 mg planta-1 de $\mathrm{N}$ ), admitiu-se que praticamente todo o N na MSPA foi resultante da FBN. Quanto à MSN por planta, estes quatro isolados foram superiores a todos os outros, observando-se, assim, a mesma tendência ocorrida para o $\mathrm{N}_{\mathrm{ac}}$. Diferenças na eficiência de estirpes derizóbios em promover estes benefícios às plantas são freqüentemente encontradas na literatura (Santillana et al., 1998; Carvalho \& Stamford, 1999).

As três culturas isoladas de nódulos de feijão-deporco apresentaram nodulação e eficiência simbiótica inexpressivas para o guandu, não se diferenciando do tratamento não inoculado e não adubado com N mineral. Segundo este resultado, pode ocorrer, entre alguns rizóbios tropicais, determinado grau de especificidade com os hospedeiros quanto à nodulação e eficiência de promover o crescimento das plantas. Thies et al. (1991) observaram que rizóbios isolados de caupi apresentaram capacidade diferenciada de nodular siratro, amendoim e feijão-lima.

Correlações altamente significativas foram observadas entre a massa de nódulos e as variáveis MSPA, AF e Nac (Figura 1).

A extração de seiva xilemática para quantificação de $\mathrm{N}$-ureído e $\mathrm{N}$-total, visando estimar a eficiência da FBN, foi possível em apenas $24 \%$ das plantas amostradas. Esta dificul dade de extração da seiva é relatada como sendo uma das principais desvantagens deste método (Peoples et al., 1989). Correlações significativas foram encontradas entre 
Quadro 2. Área foliar (AF), matéria seca da parte aérea (MSPA), matéria seca dos nódulos (MSN) e $\mathbf{N}$ total acumulado $\left(\mathrm{N}_{\mathrm{ac}}\right)$ na parte área de plantas de guandu (Cajanus cajan), submeti das a tratamentos com doses crescentes de $\mathbf{N}$ mineral ou inoculadas com dezesseis isolados de rizóbios nativos dos tabuleiros costeiros

\begin{tabular}{|c|c|c|c|c|}
\hline Tratamento & AF & MSPA & MSN & $\mathbf{N}_{\mathrm{ac}}$ \\
\hline & $\mathrm{cm}^{2}$ planta-1 $^{-1}$ & g planta-1 & \multicolumn{2}{|c|}{ _ mg planta-1 _ } \\
\hline $0 \mathrm{~N}$ & $50 \mathrm{~g}^{*}$ & $0,27 \mathrm{~g}$ & $0 \mathrm{~d}$ & $4 d$ \\
\hline $50 \mathrm{~N}$ & 266 efg & 1,63 efg & $0 \mathrm{~d}$ & $31 d$ \\
\hline $100 \mathrm{~N}$ & 537 cde & 3,74 cde & $0 \mathrm{~d}$ & $65 c$ \\
\hline $150 \mathrm{~N}$ & $539 \mathrm{~cd}$ & $4,11 \mathrm{~cd}$ & $0 \mathrm{~d}$ & $74 \mathrm{c}$ \\
\hline R1 & $1.035 \mathrm{a}$ & $7,08 \mathrm{a}$ & $497 a$ & $186 a$ \\
\hline $\mathrm{R} 2$ & $191 \mathrm{fg}$ & $1,06 \mathrm{fg}$ & $101 \mathrm{~cd}$ & $26 d$ \\
\hline R3 & 393 defg & 2,30 defg & 254 bc & $63 c$ \\
\hline R4 & $19 \mathrm{~g}$ & $0,14 \mathrm{~g}$ & $5 d$ & $3 d$ \\
\hline R5 & 810 bc & $5,23 \mathrm{bc}$ & $449 a$ & $151 \mathrm{~b}$ \\
\hline R6 & 312 def & 1,80 def & $153 \mathrm{bc}$ & $68 c$ \\
\hline R7 & 417 def & 2,49 def & $210 \mathrm{bc}$ & $67 c$ \\
\hline R8 & $875 a b$ & $6,04 a b$ & $436 a$ & $155 a b$ \\
\hline R9 & 223 efg & 1,31 efg & $66 \mathrm{~cd}$ & $54 \mathrm{~cd}$ \\
\hline $\mathrm{R} 10$ & 567 def & 3,08 def & $284 \mathrm{~b}$ & $87 c$ \\
\hline $\mathrm{R} 11$ & 980 a & 6,99 a & $433 a$ & 191 a \\
\hline $\mathrm{R} 12$ & $35 \mathrm{~g}$ & $0,22 \mathrm{~g}$ & $4 d$ & $3 d$ \\
\hline $\mathrm{R} 13$ & $26 \mathrm{~g}$ & $0,17 \mathrm{~g}$ & $10 \mathrm{~d}$ & $4 d$ \\
\hline $\mathrm{R} 14$ & $25 \mathrm{~g}$ & $0,23 \mathrm{~g}$ & $0 \mathrm{~d}$ & $3 d$ \\
\hline R15 & $72 \mathrm{~g}$ & $0,37 \mathrm{~g}$ & $39 \mathrm{~d}$ & $9 d$ \\
\hline $\mathrm{R} 16$ & $97 \mathrm{~g}$ & $0,58 \mathrm{~g}$ & $39 \mathrm{~d}$ & $19 d$ \\
\hline
\end{tabular}

Médias seguidas por uma mesma letra não diferem entre si pelo teste de Duncan a $5 \%$.

a relação $\mathrm{N}$-ureído/ $\mathrm{N}$-total na seiva e as variáveis MSN e $\mathrm{N}_{\mathrm{ac}}$ (Figura 2). De acordo com Neves et al. (1985) e Hungria \& Neves (1986), as associações entre rizóbios eficientes e cultivares desoja ou feijão com alto potencial deFBN resultaram notransporte de uma concentração maior do $\mathrm{N}$-total sob a forma de N-ureído na seiva xilemática destas plantas.

Dentreos isolados de rizóbios sel ecionados quanto à FBN em vasos de Leonard, os três escol hidos para a caracterização foram R1, R5 e R11, visto que ocorreram dificul dades técnicas durantea tentativa de caracterização do isol ado R8.

Os tempos de geração dos isolados R1, R5 e R 11 foram de 1,59; 1,20 e 1,25 h, respectivamente, estando estes val ores bem abaixo daqueles de 2,5 a 4,0 h, normal mente citados para bactérias do gênero Rhizobium (Giller \& Wilson, 1991).

Após sete dias de incubação, as colônias de R1 e R5 apresentaram grande quantidade de um muco de consistência aquosa, com características semel hantes ao muco do tipo I, descrito por Martins et al. (1997) e Xavier et al. (1998), ao passo que colônias de R11 apresentaram muco menos abundante e de consistência semel hante à do muco do tipoll.
Os isolados $\mathrm{R} 1$ e $\mathrm{R} 5$ apresentaram resistência elevada ao ácido nalidíxico, ao cloranfenicol e à ampicilina e, ainda, resistência moderada à kanamicina (Quadro 3). O isolado R11, no entanto,
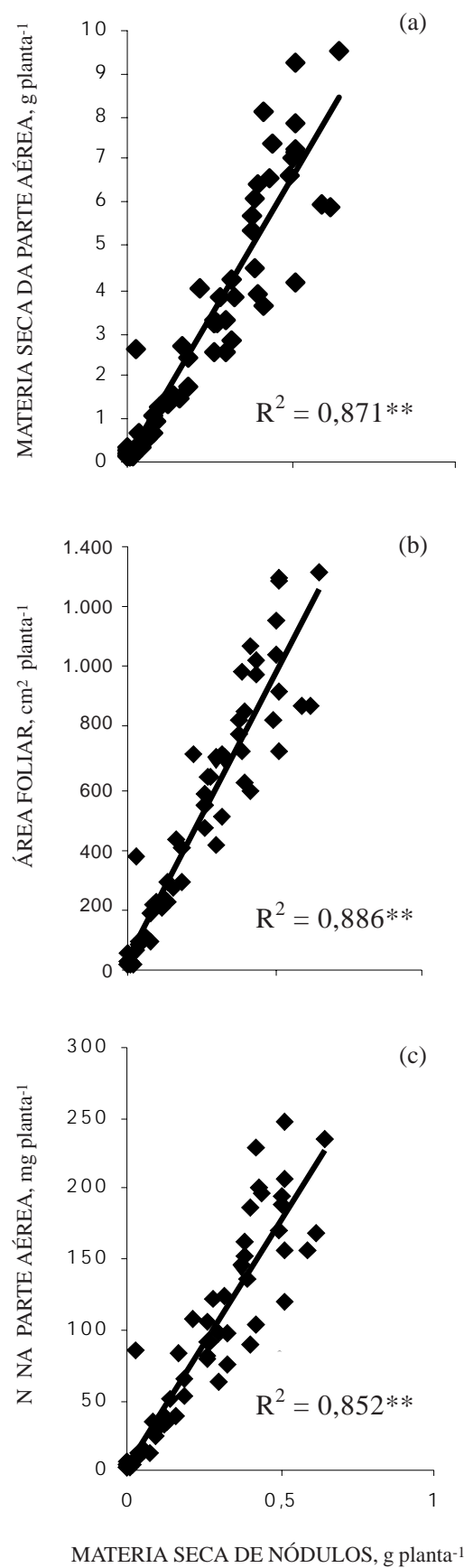

Figura 1. Correlações entre a matéria seca de nódulos por planta e as variáveis matéria seca de parte aérea (a), área foliar (b) e N acumulado na parte aérea (c) de plantas de guandu, submetidas à inoculação com diferentes rizóbios nativos dos tabuleiros costeiros. Os dados dos tratamentos sem inoculação não foram considerados. 


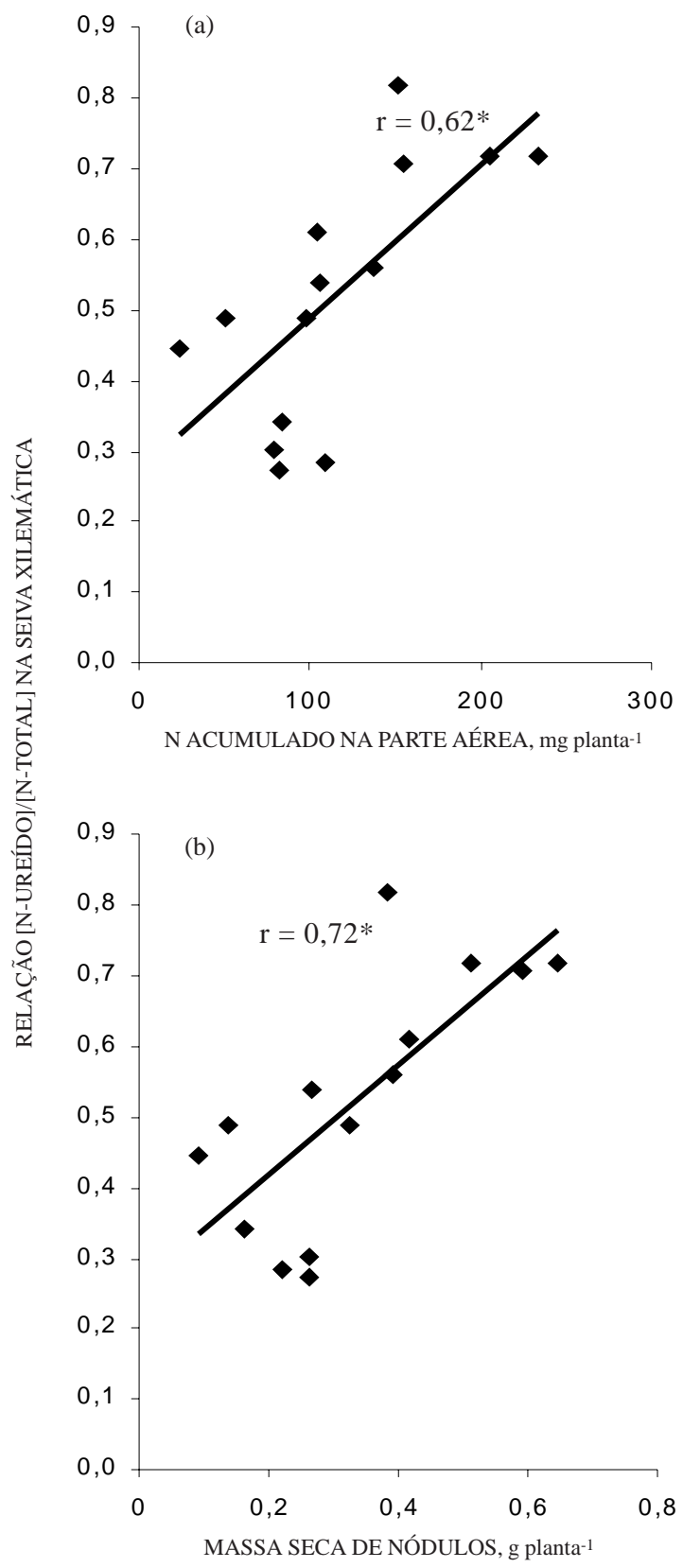

Figura 2. Correlação entre os valores de [N-ureído]/ [N-total] na seiva xilemática de guandu e as variáveis $\mathbf{N}$ total acumulado na parte aérea (a) e matéria seca de nódulos por planta (b). caracterizou-se por sua alta suscetibilidade a todos os antibióticos, com exceção ao ácido nalidíxico. Observou-se, assim, relação direta entre resistência a antibióticos e produção de muco, como relatado por Sinclair \& Eaglesham (1984).

Xavier et al. (1998) observaram que estirpes de rizóbios com resistência a anti bióticos têm sido mais freqüentemente isoladas em sol o com Al, o que pode indicar a existência de uma rel ação entreestas duas características em rizóbios. Esta tendência também foi encontrada neste trabalho, cujos dados indicam que R1 e R5, isolados com maior resistência a antibióticos, também foram os mais tolerantes ao Al. Tais isolados apresentaram crescimento em meio com concentrações de até $20 \mathrm{mg} \mathrm{L}-1$ de Al, o mesmo não acontencedo para R11, cujo crescimento foi observado apenas até $10 \mathrm{mg} \mathrm{L}^{-1}$ de Al.

De acordo com alguns autores, a alta produção de muco por estirpes de rizóbio estaria ainda associada à capaci dade destas bactérias em tolerar altas temperaturas (Osa-Afiana \& Alexander, 1982; Hollingsworth et al., 1985). Esses resultados são corroborados pelos dados obtidos neste estudo, que indicam maior tolerância dos isolados R 1 e R5 à el evação da temperatura de incubação, comparativamente ao R11. As colônias dos isolados R1 e R5, incubados a $32^{\circ} \mathrm{C}$, apresentaram cerca de $75 \%$ do diâmetro das col ônias crescidas a ${ }^{28} \mathrm{C}$, temperatura considerada ótima para o crescimento de rizóbios. A $42^{\circ} \mathrm{C}$, o diâmetro das colônias desses isolados foi reduzido para apenas $12 \%$ do observado a $28^{\circ} \mathrm{C}$. A temperatura de incubação de $32^{\circ} \mathrm{C}$ foi suficiente para inibir por completo o crescimento do isolado R11.

Quanto à al teração no $\mathrm{pH}$ do meio decultura que continha manitol, os três isolados promoveram a acidificação do meio YMA. Tal acidificação foi observada aos dois dias de incubação, para R1 eR5, e aos quatro dias, para R11.

As características de rápido crescimento, a acidificação do meio de cultura com manitol e a grande produção de muco foram observadas em 13 das 16 estirpes avaliadas (resultados não mostrados), o que pode indicar que este seja um padrão freqüente de rizóbios nativos dos sol os de tabuleiros costeiros capazes de nodular o guandu, o feijão-de-porco e o caupi.

Quadro 3. Resistência intrínseca a antibióticos de três isolados de rizóbios nativos dos tabuleiros costeiros, determinada pelo método do gradiente em placa, com concentrações variando de 0 a $500 \mathrm{mg} \mathrm{L}^{-1}$

\begin{tabular}{ccccccc}
\hline Isolado & Ac. nalidíxico & Estreptomicina & Kanamicina & Cloranfenicol & Tetraciclina & Ampicilina \\
\hline R1 & 3 & 0 & 1 & 3 & 0 & 3 \\
R5 & 3 & 0 & 1 & 3 & 0 & 3 \\
R11 & 2 & 0 & 0 & 0 & 0 & 0
\end{tabular}

0: resistente de 0 a $125 \mathrm{mg} \mathrm{L}^{-1}$; 1: resistente de 126 a $250 \mathrm{mg} \mathrm{L}^{-1}$; 2: resistente de 251 a $375 \mathrm{mg} \mathrm{L}^{-1}$; 3: resistente de 376 a $500 \mathrm{mg} \mathrm{L}^{-1}$. 


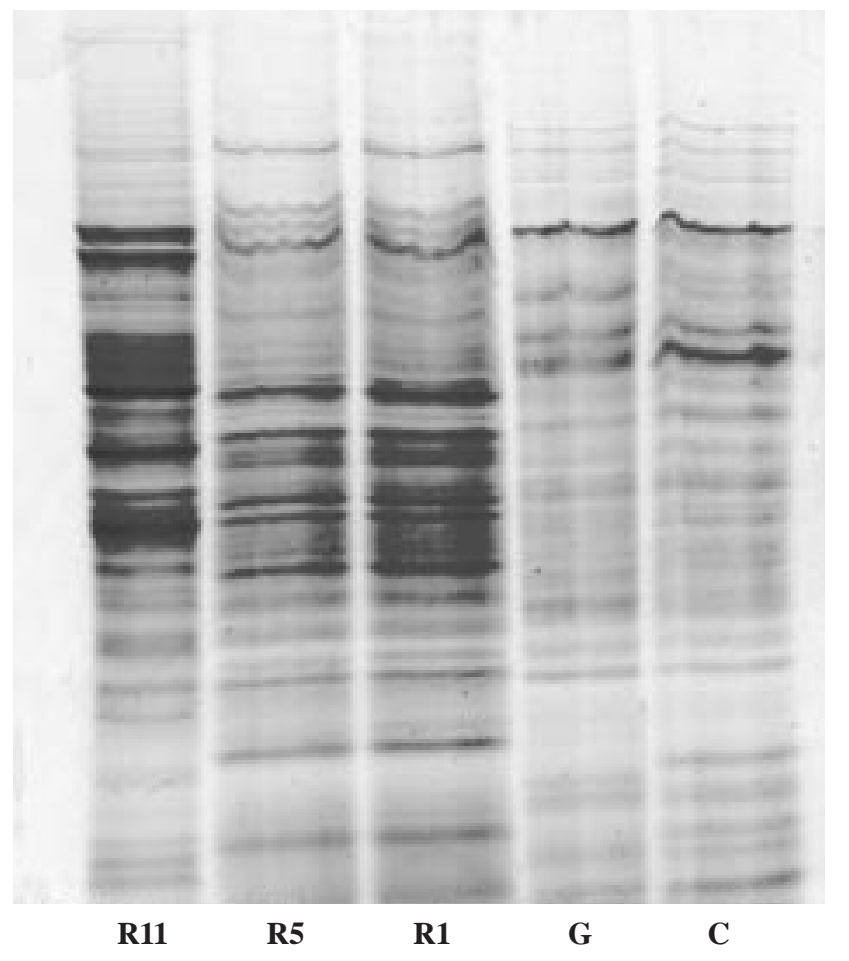

Figura 3. Perfil eletroforético de proteínas totais solúveis dos isolados de rizóbios R 1, R5 e R11 e de estirpes de crescimento lento, recomendadas para guandu (G) e caupi (C), provenientes da E mbrapa Agrobiologia.

A semel hança entre $\mathrm{R} 1$ e $\mathrm{R} 5$ e as diferenças entre estes e R11 também foram comprovadas pela avaliação do perfil el etroforético de proteínas totais dessas bactérias (Figura 3).

\section{CONCLUSÃO}

Dois isolados de rizóbios nativos de tabuleiros costeiros obtidos neste estudo (R1 e R5) revelaram grande potencial de utilização como inoculante de guandu, por apresentarem alta capacidade de fixação biológica do $\mathrm{N}$ e características que favorecem a sobrevivência no solo.

\section{AGRADE CIMENTOS}

À F undação Banco do Brasil, pel ofinanciamento deste trabalho; ao Assistente de Pesquisa J adson Alves do Nascimento eaos estagiários Carlos Aurélio Alves Oliveira eH osanaide Batista dos Santos, pelo apoio dado na realização dos experimentos.

\section{LITE RATURA CITADA}

BARRETO, A.C. \& FERNANDES, M.F. Recomendação de leguminosas para adubação verde em solos dos tabuleiros costeiros. Aracaju, Empresa Brasileira de Pesquisa Agropecuária, 1998. 5p. (EMBRAPA - CPATC. Comunicado Técnico, 28)

BRADFORD, M.M. A rapid and sensitive method for the quantification of micrograms of protein utilizing the principle of protein-dye binding. Anal. Biochem., 72:248$254,1976$.

BROCKWELL, J . Can inoculant strains ever competesuccessfully with estabilished soil populations? In: GIBSON, A.H. \& NEWTON, W.E., eds. Current perspectives in nitrogen. Amsterdan, North Holland/Elsevier, 1981. p.277-315.

CARVALHO, F.G. \& STAMFORD, N.P. Fixação do $\mathrm{N}_{2}$ em leucena (Leucaena leucocephala) em solo da região semi-árida brasileira submetido à salinização. R. Bras. Ci. Solo, 23:237243, 1999.

GILLER, K.E. \& WILSON, K.J . Nitrogen fixation in tropical cropping systems. Wallingford, C.A.B. International, 1991. $313 p$.

HOLLINGSWORTH, R.; SMITH, E. \& AHMAD, M.H. Chemical composition of extracellular polysaccharides of cowpea rhizobia. Arch. Microbiol., 142:18-20, 1985.

HUNGRIA, M. Metabolismo do carbono e do nitrogênio nos nódulos. In: HUNGRIA, M. \& ARAÚj O, R., eds. Manual de métodos empregados em estudos de microbiologia agrícola. Brasília, Empresa Brasileira de Pesquisa Agropecuária, 1994. p.249-279.

HUNGRIA, M.; VARGAS, M.A.T.; SUHET, A.R.; PERES, J .R.R. \& MENDES, I.C. I dentificação de parâmetros relacionados com a eficiência e capacidade competitiva do rizóbio. In: HUNGRIA, M. \& ARAÚj O, R., eds. Manual de métodos empregados em estudos de microbiologia agrícola. Brasília, Empresa Brasileira de Pesquisa Agropecuária, 1994. p.285325.

HUNGRIA, M. \& NEVES, M.C.P. Ontogenia da fixação biológica do nitrogênio em Phaseol us vulgaris. Pesq. Agropec. Bras., 21:715-730, 1986.

LAEMMLI, U.K. Cleavage of structural proteins during the assembly of the head of bacteriophage T4. Nature, 227:680$685,1970$.

MARTINS, L.M.V.; XAVIER, G.R.; NEVES, M.C.P. \& RUMJ ANEK, N.G. Características relativas ao crescimento em meio de cultura e a morfologia de colônias de "rizóbio". Seropédica, Empresa Brasileira de Pesquisa Agropecuária, 1997. 14p. (E mbrapa-CNPAB. Comunicado Técnico, 19)

NEVES, M.C.P.; DIDONET, A.D.; DUQUE, F.F . \& DÖBEREINER, $J$. Rhizobium strain effects on nitrogen transport and distribution in soybeans. J .Exp. Bot., 36:1179-1192, 1985.

OLIVEIRA, L.A. \& GRAHAM, P.H. Evaluation of strain competitiveness in Rhizobium legumi nosarum bv. phaseol $\mathrm{i}$ using a nod+fix- natural mutant. Arch. Microbiol., 54:305310, 1990.

OSA-AFIANA, L.O. \& ALEXANDER, M. Clays and the survival of Rhizobium during desiccation. Soil Sci. Soc. Am. J., 46:285-288, 1982. 
PEOPLES, M.B.; HEBB, D.M.; GIBSON, A.H. \& HERRIDGE, D.F. Development of the xylem ureide assay for measurement of nitrogen fixation by pigeonpea (Cajanus cajan (L.) Millsp.). J . Exp. Bot., 40:535-542, 1989.

SANTILLANA, N.; FREIRE, J .R.J .; SÁ, E.L.S. \& SATO, M. Avaliação de estirpes de rizóbios para a produção de inoculantes para trevo vermelho. R. Bras. Ci. Solo, 22:231237, 1998.

SINCLAIR, M.J . \& EAGLESHAM, A.R.J . Intrinsic antibiotic resistance in relation to colony morphology in three populations of west African cowpea rhizobia. Soil Biol. Biochem., 16:247-251, 1984.

THIES, J .E.; BOHLOOL, B.B. \& SINGLETON, P.W. Subgroups of the cowpea miscellany: symbiotic specificity within Bradyrhizobium spp. for Vigna unguiculata, Phaseolus Iunatus, Arachis hipogaea and Macroptilium atropurpureum. Appl. Environ. Microbiol., 57:1540-1545, 1991.
VINCENT, J.M. Manual for the practical study of root nodule bacteria. Oxford, Blackwell, 1970. 164p.

VOGELS, G.D. \& van der DRIFT, C. Differential analysis of glyoxilate derivatives. Anal. Biochem., 33:143-157, 1970.

WEAVER, R.W. \& FREDERICK, L.R. Rhizobium In: PAGE, A.L.; MILLER, R.H. \& KEENEY, D.R. Methods of soil analysis Part 2 - Chemical and microbiological properties. 2 ed. Madison, American Society of Agronomy, 1982. p.1043-1070.

WOLFF, A.B.; STREIT, W.; KIPE-NOLT, J .A.; VARGAS, H. \& WERNER， D. Competitiveness of Rhizobium leguminosarum bv. phaseoli strains in relation to environmental stress and plant defense mechanisms. Biol. Fertil. Soils, 12:170-176, 1991.

XAVIER, G.R.; MARTINS, L.M.V.; NEVES, M.C.P. \& RUMJ ANEK, N.G. Edaphic factors as determinants for the distribution of intrinsic antibiotic resistence in a cowpea rhizobia population. Biol. Fertil. Soils, 27:386-392, 1998. 
